\title{
Consumer Purchasing Behaviour for Fresh Vegetables in Nanjing, China
}

\author{
A. Liu, L. Xu and S. Zhou \\ Nanjing Agricultural University \\ Nanjing \\ China
}

\author{
P.J. Batt \\ Curtin University \\ Perth \\ Australia
}

Key words: consumer behaviour, vegetable, food safety, safe vegetable

\begin{abstract}
With increasing income and growing concerns for food safety, consumer purchasing behaviour for fresh vegetables is changing in China. To gain a better understanding of consumer behaviour in Nanjing, 542 face-to-face interviews were conducted. Results show that most fresh vegetables are purchased from traditional wet markets several times per week. In evaluating the quality of the fresh vegetables respondents intended to purchase, the two key selection criteria were colour and freshness. Most respondents were aware of some recent food safety incident that had adversely affected the industry. Respondents were most concerned about the presence of pesticide residues. To reduce the possibilities of contamination, respondents chose to wash or soak the fresh vegetables they intended to eat and to buy from trusted suppliers. Consumers believed that farmers, vegetable processors and government should be responsible for the enhancing and maintaining the safety of the fresh vegetables offered for sale.
\end{abstract}

\section{INTRODUCTION}

Consumer behaviour is increasingly driven by factors related to food quality, safety and health. In the wake of numerous food safety scandals, the safety of food products worldwide is receiving much greater attention. Today, consumers all over the world demand high quality wholesome food products at reasonable prices. They also need to be protected from food-related illnesses which may arise at any level of the supply chain (FAO, 2004). As China's national income has rapidly risen, the consumer demand for high quality food has also risen. After a series of food safety incidents, China is trying to satisfy the domestic demand for high quality and safe food products by promoting the production of organic foods, green foods, pollution-free agricultural products and other eco-friendly agricultural products (Chung, 2011). A study of consumers' perceptions towards the quality and safety of fish products in Beijing demonstrated a lack of food safety knowledge among customers, including processing, storage and traceability systems. The consumers' age, educational level, their perceptions of food safety and price were the main determinants of Beijing consumer's willingness to pay for quality assured products (Wang et al., 2009).

Fruit and vegetables are an important component of a healthy diet and, if consumed daily in sufficient amounts, can help prevent major diseases such as cardio vascular disease and certain cancers (WHO, 2004). As the purchase of fresh vegetables is very much a routine purchase, consumers use a limited number of criteria in their decision to purchase. In Armenia, Shen (2010) was able to demonstrate that freshness, price, external appearance, colour and taste were the criteria most often used by consumers in 
making their decision to purchase. In Sri Lanka, the variables most often considered by consumers' included: price (57\%), appearance (52\%), freshness $(40 \%)$ and nutritional value $(42 \%)(J a y a t i l l a k e$ and Mahalianaarachchi, 2007). In Slovenia, Kuhar and Juvancic (2010) demonstrated how the decision to purchase was influenced by the availability of retail outlets, the consumer's income, health and environmental considerations, and the visual attractiveness of the products.

In China, Liu (2002) showed that eight variables influenced the consumer's decision to purchase fresh vegetables: habit, fashion, convenience, price comparison, loyalty, preference and the desire to find something new. In Nanjing, Qu (2007) showed how fresh vegetable prices and freshness were the major factors influencing the consumers' decision to purchase fresh vegetables in a modern supermarket.

Nanjing, the capital city of Jiangsu province, China, is a city with over 7.4 million inhabitants. The average income of urban residents reached RMB 25504 in 2009. With increasing income, consumers in Nanjing are becoming more concerned about food quality and food safety issues.

To gain a better understanding of consumer behaviour towards fresh vegetables in Nanjing, a total of 600 interviews were undertaken by students from Nanjing Agricultural University from November to December 2011.

\section{METHODOLOGY}

After a comprehensive literature review and discussions with industry experts, a comprehensive questionnaire was developed. The first part of the questionnaire included a number of warm-up questions about when and where respondents last purchased fresh vegetables, what kind of vegetables they purchased, the quantity purchased and how much was spent on purchasing fresh vegetables. In Part Two, respondents were asked to indicate what criteria they used to purchase fresh vegetables, how they evaluated the quality of fresh vegetables and any concerns about food safety. Respondents were asked to recall the frequency with which they had heard about food safety issues, what kinds of issues they could recall and who should be responsible for improving food safety. Respondents were finally asked what steps they undertook or proposed to undertake to reduce the risks associated with food safety issues in the fresh vegetable industry. To conclude, some socio-demographic information was obtained from respondents.

The questionnaire was pre-tested and administered through face-to-face interviews among respondents who purchased fresh vegetables in urban areas of Nanjing. The data preparation process included editing, coding and transcribing. Coding the unstructured questions meant assigning a numerical code to each of the respondent's comments. This allowed the questions to be statistically analyzed using SPSS 16.0.

\section{RESULTS}

A total of 542 respondents responded to the survey instrument. The majority of the respondents were female (67\%). The largest group of respondents was aged 40-44 years $(16 \%)$, followed by respondents aged 30-24 years (15\%). Most respondents $(42 \%)$ had a household income from RMB 50,000 to 100,000. Over 33\% of the respondents had a four year university degree, followed by $20 \%$ of the respondents with 12 years of education. The majority of the respondents lived in a household with 3 people $(36 \%)$, followed by those respondents who lived in a four person household $(26 \%)$. Some $48 \%$ of respondents had at least one retired person living with them, and $48 \%$ had a child aged less than 20 years. 


\section{Fresh vegetable purchasing}

Most of the respondents had purchased fresh vegetables within the last two days $(73 \%)$, while $52 \%$ had purchased fresh vegetables the day before. The traditional wet market was the main place to buy fresh vegetables (51\%), followed by supermarkets $(27 \%)$, vegetable wholesalers $(8 \%)$ and roadside markets $(6 \%)$.

Tomato $(76 \%)$, cucumber $(57 \%)$, cabbage $(70 \%)$, celery $(52 \%)$, potato $(63 \%)$ and chili $(55 \%)$ were more frequently purchased by respondents. On average, most respondents bought $1.55 \mathrm{~kg}$ and spent RMB 8.4 on the last occasion that they purchased fresh vegetables.

When respondents went to purchase fresh vegetables, freshness (5.5), colour (4.8), and appearance (4.7) were considered the most important variables, while convenient packaging (3.07) and brand (2.9) were less important (where 1 was "not at all important" and 6 was "very important"). However, only 54\% of the respondents were confident in their ability to identify good quality vegetables. When asked how they selected good quality, the most frequently cited responses included colour (39\%), freshness (27\%), shape (13\%) and appearance (13\%)(Table 1).

\section{Attitudes towards food safety}

Most respondents were aware of some recent food safety incidents affecting fresh vegetables (Table 2). When asked about the food safety issues respondents' most often considered, pesticide residues $(76 \%)$ was the greatest concern, followed by the lack of freshness (14\%) and the presence of food additives (9\%), too much fertilizer (8\%), pollution (5\%), artificial colouring agents (4\%) and ripening agents (3\%)(Table 3 ).

\section{Ways to reduce food safety issues}

To reduce the issues associated with food safety, respondents most often washed the vegetables $(30 \%)$ or soaked them in water $(22 \%)$ prior to use. Other options included purchasing from a safe and regular place (13\%), selecting more carefully $(11 \%)$, purchasing from supermarkets $(9 \%)$ or self-production $(8 \%)$ (Table 4$)$. Less than $2 \%$ of respondents indicated that they were willing to purchase organic vegetables.

\section{DISCUSSION AND CONCLUSION}

Respondents in Nanjing purchased fresh vegetables frequently and generally consumed what they had purchased within three days. While the wet market was still the main place to purchase fresh vegetables, due primarily to freshness, the market share for modern supermarkets is rapidly increasing. As the literature suggests, freshness was one of the variables most often used to select fresh vegetables in a retail store, however, the most frequently cited variable was colour.

Pesticide residues were identified as the major food safety threat. To minimize the perceived risk of food poisoning, most respondents were taking some actions such as washing or soaking the vegetables prior to use.

\section{ACKNOWLEDGEMENTS}

Thanks to National Social Science Foundation Key Project "The formation of resource-saving and environment-friendly agricultural industrial system (08AJY048)" for financial assistance. 


\section{Literature cited}

Chung, C. 2011. The rapidly rising quality of Chinese agricultural products. POSRI Chindia Quarterly (Autumn): 111-117.

FAO. 2004. Food engineering, quality and competitiveness in small food industry systems with emphasis on Latin America and the Caribbean. FAO Agricultural Services Bulletin 156.

Jayatillake, J. and Mahalianaarachchi, R.P. 2007. Behavioural pattern of fruit and vegetable consumers in the "pola" system in Monaragalla district in Sri Lanka. The Journal of Agricultural Sciences 3(1): 33-42.

Kuhar, A. and Juvancic, L. 2010. Determinants of purchasing behavior for organic and integrated fruits and vegetables in Slovenia. Agricultural Economics Review 11(2): 70-82.

Nanjing Bureau of Statistics. 2010. Nanjing National economy and social development in 2009.

$\mathrm{Ou}$, H. 2007. A survey on vegetable consumer purchasing behaviour. Shanghai Vegetable 4: $11-14$.

Shen, N.G.O. 2010. Consumption Habits and Purchasing Behaviour Survey Report.

Liu, F. 2002. A study of vegetable consumer purchasing psychology. Shanghai vegetable 4: 8-9.

Wang, F., Zhang, J., Mu, W., Fu, Z. and Zhang, X. 2009. Consumers' perception toward quality and safety of fishery products, Beijing, China. Food Control, 20: 918-922. 
Table 1: How to Identify Vegetable Quality

\begin{tabular}{|c|c|c|c|c|c|}
\hline & Method 1 & Method 2 & Method 3 & $\mathrm{~N}$ & Percent \\
\hline Check color & 125 & 31 & 4 & 160 & 38.8 \\
\hline Check fresh & 71 & 33 & 8 & 112 & 27.2 \\
\hline Check shape & 28 & 27 & 1 & 56 & 13.6 \\
\hline Check appearance & 45 & 6 & 2 & 53 & 12.9 \\
\hline Check whether broken & 19 & 12 & 6 & 37 & 9.0 \\
\hline Experience & 24 & 7 & & 31 & 7.5 \\
\hline No methods & 27 & & & 27 & 6.6 \\
\hline Smell odor & 5 & 16 & 1 & 22 & 5.3 \\
\hline Inquiring farmers & 8 & 3 & 10 & 21 & 5.1 \\
\hline Observation & 17 & 3 & 1 & 21 & 5.1 \\
\hline Check taste & 4 & 12 & 2 & 18 & 4.4 \\
\hline Check price & 3 & 1 & 13 & 17 & 4.1 \\
\hline Feel by hand & 1 & 10 & 3 & 14 & 3.4 \\
\hline Check packaging & 6 & 4 & 1 & 11 & 2.7 \\
\hline Check QA & 6 & 2 & 1 & 9 & 2.2 \\
\hline Check origin of product & 2 & 2 & 3 & 7 & 1.7 \\
\hline Check hydra of vegetable & 1 & 1 & 4 & 6 & 1.5 \\
\hline Compare with other sellers & 2 & 2 & 2 & 6 & 1.5 \\
\hline Check pesticide agents & & 4 & 1 & 5 & 1.2 \\
\hline Check media report & 5 & & & 5 & 1.2 \\
\hline Listen to others & 3 & 1 & & 4 & 1.0 \\
\hline Comparing with grow own vegetable & 3 & 1 & & 4 & 1.0 \\
\hline No Insects & 2 & 2 & & 4 & 1.0 \\
\hline Try to reduce in-season vegetable & 1 & & 2 & 3 & 0.7 \\
\hline Buy from trusted Retailer & 2 & & & 2 & 0.5 \\
\hline Check Market Inspection information & 1 & & & 1 & 0.2 \\
\hline Check label & & 1 & & 1 & 0.2 \\
\hline Check brand & & 1 & & 1 & 0.2 \\
\hline Different with different vegetable & 1 & & & 1 & 0.2 \\
\hline Total & 412 & & & & \\
\hline
\end{tabular}

Table 2: Frequency of Hearing of Vegetable Food Safety Issues

\begin{tabular}{lcc}
\hline & Frequency & Percentage $(\%)$ \\
\hline Never & 33 & 6.1 \\
Occasionally & 267 & 49.4 \\
A lot & 146 & 27.0 \\
Frequently & 94 & 17.4 \\
Total & 540 & 100.0 \\
\hline
\end{tabular}


Table 3: Vegetable Safety Issues

\begin{tabular}{|c|c|c|c|c|c|}
\hline & Issue 1 & Issue 2 & Issue 3 & $\mathrm{~N}$ & Percent \\
\hline Pesticide residue & 287 & 37 & 8 & 331 & 75.8 \\
\hline Not fresh & 24 & 34 & 8 & 66 & 15.0 \\
\hline Additives & 14 & 20 & 6 & 40 & 9.2 \\
\hline Too much fertilizer & 7 & 23 & 3 & 33 & 7.6 \\
\hline Pollution & 14 & 8 & & 22 & 5.0 \\
\hline Pigment & 2 & 3 & 14 & 19 & 4.4 \\
\hline Ripening agent & 5 & 8 & 2 & 15 & 3.4 \\
\hline GM & 8 & 5 & 2 & 15 & 3.4 \\
\hline Vegetable processing problem & 2 & 10 & 1 & 13 & 3.0 \\
\hline Food safety & 7 & 1 & 1 & 9 & 2.1 \\
\hline Soaked in syrup & 7 & 1 & 1 & 9 & 2.1 \\
\hline Long storage time & 8 & 1 & & 9 & 2.1 \\
\hline Preservative & 3 & 3 & 2 & 8 & 1.8 \\
\hline Shoddy & 4 & 3 & & 7 & 1.6 \\
\hline Not clean & 10 & & 1 & 11 & 1.6 \\
\hline Poor inspection & 5 & 1 & 1 & 7 & 1.6 \\
\hline Poor taste & 6 & 1 & & 7 & 1.6 \\
\hline Heavy metal & 2 & 5 & & 7 & 1.6 \\
\hline Insect pests & 2 & 2 & 1 & 5 & 1.1 \\
\hline Poor production & 5 & & & 5 & 1.1 \\
\hline Poor market hygiene & 4 & & & 4 & 0.9 \\
\hline Too expensive & 2 & 2 & & 4 & 0.9 \\
\hline Poor packaging and transportation & 3 & 1 & & 4 & 0.9 \\
\hline Not healthy & & 4 & & 4 & 0.9 \\
\hline In-season vegetable & & 3 & 1 & 4 & 0.9 \\
\hline Add water & 1 & 3 & & 4 & 0.9 \\
\hline Hormone & 1 & 2 & & 3 & 0.7 \\
\hline Poisoning & 3 & & & 3 & 0.7 \\
\hline Broken & 3 & & & 3 & 0.7 \\
\hline Gives short weight & & 3 & & 3 & 0.7 \\
\hline Unclear of vegetable origin & 1 & 1 & & 2 & 0.4 \\
\hline Total & 436 & & & & \\
\hline
\end{tabular}


Table 4: Ways to Reduce Vegetable Food Safety Issues

\begin{tabular}{|c|c|c|c|c|c|}
\hline & $\begin{array}{c}\text { Method } \\
1 \\
\end{array}$ & $\begin{array}{c}\text { Method } \\
2 \\
\end{array}$ & $\begin{array}{c}\text { Method } \\
3 \\
\end{array}$ & $\mathrm{~N}$ & Percent \\
\hline Wash more times & 87 & 32 & 1 & 106 & 30.0 \\
\hline Soak & 78 & 13 & & 91 & 22.0 \\
\hline Buy from safe and regular place & 40 & 15 & & 55 & 13.3 \\
\hline Select more carefully & 39 & 5 & 2 & 46 & 11.1 \\
\hline Buy from supermarket & 31 & 5 & & 36 & 8.7 \\
\hline Self-production & 17 & 5 & 13 & 35 & 8.5 \\
\hline Buy from fixed retailer & 9 & 13 & & 22 & 5.3 \\
\hline Try to select fresh vegetable & 14 & 1 & 1 & 16 & 3.9 \\
\hline Peel the skin & & 7 & 8 & 15 & 3.6 \\
\hline Use liquid for washing vegetable and fruit & 11 & 3 & & 14 & 3.4 \\
\hline Buy from village & 6 & 1 & 6 & 13 & 3.1 \\
\hline Soak with salt water & 6 & 3 & 2 & 11 & 2.7 \\
\hline Try to learn knowledge about quality identification & 7 & 4 & & 11 & 2.7 \\
\hline Only eat cooked food & 6 & 3 & 2 & 11 & 2.7 \\
\hline Improve awareness of unsafe vegetable & 7 & 2 & & 9 & 2.2 \\
\hline Buy brand vegetable & 7 & 2 & & 9 & 2.2 \\
\hline Listen to media & 4 & 2 & 2 & 8 & 1.9 \\
\hline Buy organic & 5 & & 2 & 7 & 1.7 \\
\hline Buy expensive vegetable & 5 & 1 & 1 & 7 & 1.7 \\
\hline Improve quality management & 7 & & & 7 & 1.7 \\
\hline Wash with washing rice water & 6 & & & 6 & 1.4 \\
\hline Improve vegetable quality & 5 & & & 5 & 1.2 \\
\hline Try to eat season vegetable & 3 & 1 & 1 & 5 & 1.2 \\
\hline Recommendation by friends & 1 & 1 & 3 & 5 & 1.2 \\
\hline Buy vegetable that had holes on leaves & 2 & 2 & & 4 & 1.0 \\
\hline Buy local vegetable & 2 & & 1 & 3 & 0.7 \\
\hline Compare with others & 2 & 1 & & 3 & 0.7 \\
\hline Pay attention to sale date and shelf-life of vegetable & & 3 & & 3 & 0.7 \\
\hline Improve immunization levels & & 1 & 1 & 2 & 0.5 \\
\hline Check colour & 1 & 1 & & 2 & 0.5 \\
\hline Government should take care of vegetable farmers & 2 & & & 2 & 0.5 \\
\hline Ensure that every steps of food safety & 1 & & & 1 & 0.2 \\
\hline More punishment & 1 & & & 1 & 0.2 \\
\hline Media exposure & 1 & & & 1 & 0.2 \\
\hline Try to buy less vegetable & 1 & & & 1 & 0.2 \\
\hline Total & 414 & & & & \\
\hline
\end{tabular}

